\title{
Structure of the Field of the Colored Dissolved Organic Matter Concentration in the Kerch Strait
}

\author{
P. D. Lomakin ${ }^{凶}$, A. I. Chepyzhenko, A. A. Chepyzhenko \\ Marine Hydrophysical Institute of RAS, Sevastopol, Russian Federation \\ 凶p_lomakin@mail.ru
}

\begin{abstract}
Purpose. Using the data obtained in the expeditions, 2001-2014, the authors intend to identify the typical features of vertical structure of the colored dissolved organic matter (fDOM) concentration field in the Kerch Strait, to type the fDOM(z) profiles, to zone the region under consideration according to a given set of the qualitative features, and also to determine the features of statistical characteristics of the $f D O M$ concentration distribution on the sea surface layer for the water areas with a typical structure.

Methods and Results. The typing was carried out by the method of visual expert assessment of the curves of vertical distribution of concentration of the considered value. It was based on analyzing the $\mathrm{fDOM}(\mathrm{z})$ profile shapes. To reveal the boundaries of the areas with typical stratification of the fDOM content field, the thermohaline field structure was analyzed. Three types of water vertical structure were identified; they differed in the $\mathrm{fDOM}(\mathrm{z})$ profile shape and in statistical indices of empirical distribution of this substance concentration on the sea surface. These are the Azov Sea and the Black Sea types peculiar to the Azov and Black seas waters not contaminated by dissolved organic matter, and the type, the structure of which identifies the waters containing the anthropogenic component in the concentration field of the analyzed value. The latter type is characterized by a special intrusive shape of the fDOM(z) profile. For each of the identified stratification types, the histograms of the fDOM concentration distribution on the sea surface were calculated.

Conclusions. The fDOM(z) profiles were typed. The Kerch Strait water area was zoned in accordance with a given set of the preliminary revealed qualitative features. The boundaries of the areas with typical stratification and their displacements were determined. It is shown that each structure type has its own statistical distribution of concentration of the considered value on the sea surface.
\end{abstract}

Keywords: colored dissolved organic matter, stratification types, zoning, haline front, Kerch Strait

Acknowledgments: the work was carried out within the framework of the state task on themes No. 0555-2021-0003 "Development of operational oceanology methods based on interdisciplinary research of processes of the marine environment formation and evolution, and on mathematical modeling using data of remote and contact measurements" and No. 0555-2021-0005 "Complex interdisciplinary studies of oceanologic processes which determine functioning and evolution of ecosystems in the coastal zones of the Black Sea and the Sea of Azov".

For citation: Lomakin, P.D., Chepyzhenko, A.I. and Chepyzhenko, A.A., 2021. Structure of the Field of the Colored Dissolved Organic Matter Concentration in the Kerch Strait. Physical Oceanography, [e-journal] 28(5), pp. 525-537. doi:10.22449/1573-160X-2021-5-525-537

DOI: 10.22449/1573-160X-2021-5-525-537

(C) P. D. Lomakin, A. I. Chepyzhenko, A. A. Chepyzhenko, 2021

(C) Physical Oceanography, 2021

Organic matter (OM) in the sea is an integral indicator. Its value mainly depends on water trophicity, the ratio of the rates of production-destruction processes and coastal runoff value. Quantitative and qualitative study of dissolved (DOM) and suspended organic matter (SOM), variability of its concentrations, elemental and biochemical composition in time and space is necessary to understand the processes that form and support the marine ecosystem functioning and productivity [1]. 
Dissolved and suspended organic carbon (DOC and SOC, respectively) are representative indicators of the DOM and SOM content in seawater, which have been studied in the Azov-Black Sea basin since the 1940s to the present. A detailed review of publications concerning the study of the distribution of these indicators for the Black Sea waters obtained from various sources by different methods is given in [1]. In [2], statistical information on the DOC content in certain regions of the Sea of Azov and in the Kerch Strait is presented. In particular, it is known that the DOM and SOM concentrations in the Black Sea vary over a very wide range: 60-1000 $\mu \mathrm{M}$ for DOC and 2.83-104.16 $\mu \mathrm{M}$ for SOC. A more stable SOC content, according to [2], is typical for the Sea of Azov and the Kerch Strait (the Don River 7.7-15.8 mgC/l, Taganrog Bay 1.8-19.3 mgC/l, central part of the Sea of Azov 1.9-20.5 mgC/l, Kerch Strait 2.0-18.9 mgC/l).

Studies of SOM and its indicators, carried out in the Azov-Black Sea basin, mainly concern the biochemical properties of these values. There was an attempt of oceanographic research of SOC, undertaken by VNIRO employees, based on data obtained in two expeditions (15 $5^{\text {th }}$ cruise of R/V Vityaz in April 1988 and $24^{\text {th }}$ cruise of R/V Akademik Knipovich in June - July 1989). Maps of the spatial distribution of DOC concentration in the Black Sea, according to the authors of [1], are schematic due to the significant spatial-temporal variability of the studied value and the insufficient volume of empirical data sample. At the same time, they made it possible to obtain the first ideas about the DOC content field structure in the coastal area and in the oxygen zone of the deep-water Black Sea.

The present paper provides the result of an oceanological study of the DOM indicator field in the Kerch Strait - its fluorescent component determined by the optical method. In English, this value (colored dissolved organic matter) has the standard abbreviation fDOM, which is further used in the text.

The proposed work is aimed: to determine the typical signs of vertical stratification of the fDOM concentration field, specific for the Azov and Black Sea waters interacting in the Kerch Strait, as well as for waters under anthropogenic pressure; based on the identified set of features, to carry out typing of the $\operatorname{fDOM}(\mathrm{z})$ profiles and propose a zoning scheme for the studied water area; to determine the position and displacement of the boundaries of areas with typical features of the structure of the concentration field of the considered value; to calculate and analyze the statistical characteristics on the sea surface inherent to each type of fDOM field stratification.

\section{Initial data and research methods}

Since about the late 90 s of the last century, instrumental hydro-optical methods began to be used in the DOM study in the waters of the oceans, seas and other water bodies. Currently, fluorimetric DOM meters are produced by the world's leading companies. Dissolved organic matter and its fluorescent index fDOM have found wide application in world practice in solving general oceanological problems, as well as in environmental studies to assess the quality of waters of coastal ocean and sea areas, they are actively used by well-known scientific organizations, including Woods Hole Oceanographic Institution [3-10].

Since 2001, Marine Hydrophysical Institute (MHI) has introduced an optical method for operational determination of the fDOM content in situ during 
the monitoring expeditionary studies of the Kerch Strait. The empirical data array accumulated by 2014 allowed starting studying this substance concentration field structure based on the methods of classical oceanography. An obligatory stage of such a study involves the typification of vertical profiles based on a set of characteristic features of studied value field stratification and the subsequent zoning of the studied water area.

All information used in this work was obtained by means of the Kondor Optical Probing Complex (RPE Aquastandart, TR 431230-006-00241904-2015; EAEU HS code 902750000 0; EAEU certificate N RU D-RU.EM03.A.00096 / 19) (http://ecodevice.com.ru/ecodevice-catalogue/multiturbidimeter-kondor). To measure the fDOM concentration, a fluorimeter was included in the functional diagram of the meter. It facilitated the rapid collection of information about this parameter of the aquatic environment.

The fDOM concentration meter [4] is based on the optical method of fixing the fluorescent component of this substance. Spectral characteristics - sections of the emission excitation spectrum (Ex/Em) 370/450 nm - are standard for meters of the fluorescent DOM component and are used in monitoring this value field (dissolved organic matter or Carbon - DOM, DOC) [7].

The materials of the $31^{\text {st }}$ MHI expedition to the Kerch Strait (June 2001 - July 2014) were used as the initial data. The in situ sample of data from actual synchronous observations in the sounding mode of temperature, salinity, total suspended matter and fDOM included 1443 probes. All observations were carried out using the Kondor complex with a depth step of $0.1 \mathrm{~m}$, the range of studied depths is $0.5-50 \mathrm{~m}$.

702 probes carried out in the considered water area with a depth not exceeding $2 \mathrm{~m}$ were selected for the analysis. Dimension of the studied value is presented in calibration units - quinine sulfate (QSU).

The typification problem was solved in two stages. At the first stage, according to clearly expressed qualitatively different features, the waters were divided into those exposed to anthropogenic impact (localized in the form of separate lenses) and "clean" ones, which did not contain the anthropogenic component fDOM (water in the prevailing part of the studied water area). At the second stage, the Kerch Strait water area was zoned according to the characteristic structural features of the considered value field, characteristic of the "clean" Azov and Black Sea waters. In this case, the results of the analysis of the salinity field structure were used. The term "clean" waters is used for convenience of description and means waters that do not contain fDOM of anthropogenic nature.

Note that DOM and its optical determination fDOM are referred to the most informative indicators of pollution, including bacterial, of coastal waters of the oceans and seas [10-12].

\section{Discussion of the results}

Analysis of the horizontal structure of the fDOM content field according to each survey data revealed its main quality - a homogeneous background, against which separate spots (lenses) with a high content of this substance were distinguished. The vertical profiles $\operatorname{fDOM}(\mathrm{z})$ in the lenses were nonmonotonic, PHYSICAL OCEANOGRAPHY VOL. 28 ISS. 5 (2021) 
while in the surrounding waters the field stratification of this value was weak or absent.

The special arrangement of lenses with a high fDOM content which should not exist in nature and their proximity to the known objects of anthropogenic impact on the water environment of the Kerch Strait testifies to the anthropogenic origin of these formations.

Vertical profiles having signs of anthropogenic impact were combined into a separate type of fDOM field stratification and removed from the analyzed data sample. The residual sample contained information on the "clean" Azov and Black Sea waters that interact in the Kerch Strait. Analysis of this sample revealed a number of differences in the shape of the $\operatorname{fDOM}(\mathrm{z})$ profiles. To study it, it was necessary to divide the data sample common for "clean" waters into two parts with information on the Sea of Azov and Black Sea waters. Then, a transition to the analysis of profiles and quantitative statistical estimates of the fDOM concentration field structure for each of the samples was carried out.

According to classical concepts [13], waters of various origins interacting in oceans and seas have a natural boundary in the form of a frontal section. In the analyzed situation, the fDOM concentration field in the waters of the studied water area is uniform with a reduced concentration of this value in the northern part of the strait and a weakly expressed diffuse frontal section, which approximately coincided with the main thermohaline front of the Kerch Strait.

Due to the properties noted, it is extremely difficult to distinguish the front in the fDOM field and more or less unambiguously determine its position in the strait water area. Therefore, as the boundary dividing the Sea of Azov and Black Sea waters, a haline front, stable in time and clearly expressed throughout the year, was adopted. The thermal front in the Kerch Strait is less stable. In transitional seasons (from warm to cold), it is blurred and changes the horizontal gradient sign [14].

Analysis of the salinity field structure showed that for the time interval under study, the parameters of the haline front in the Kerch Strait were as follows: the frontal section width was 3-5 miles, the salinity difference at its boundaries on the surface and at the bottom was 13-16 PSU. The salinity of the transformed Azov and Black Sea waters located to the north and south of the front varied within 11-13 and 16-18 PSU, respectively.

In 2001-2014 near the Kerch coast, the front experienced significant meridional displacements. Its centerline (shown in green in Fig. 1) roughly coincided with isohalines 15 and 16 PSU. In the western part of the strait, front fluctuations are most intense with a span of $\sim 20$ miles, from the Azov narrowness to Cape Takil, located in the Black Sea pre-strait part. In the center and in the east of the Kerch Strait, the haline frontal section was inactive and was located approximately along the line of Tuzla Island - the dam (Fig. 1).

Data on the haline front was used for reliable division of the initial data filtered from the fDOM(z) profiles of anthropogenic origin into two samples, on the basis of which the structure of the "clean" Azov Sea and "clean" Black Sea waters was analyzed. 

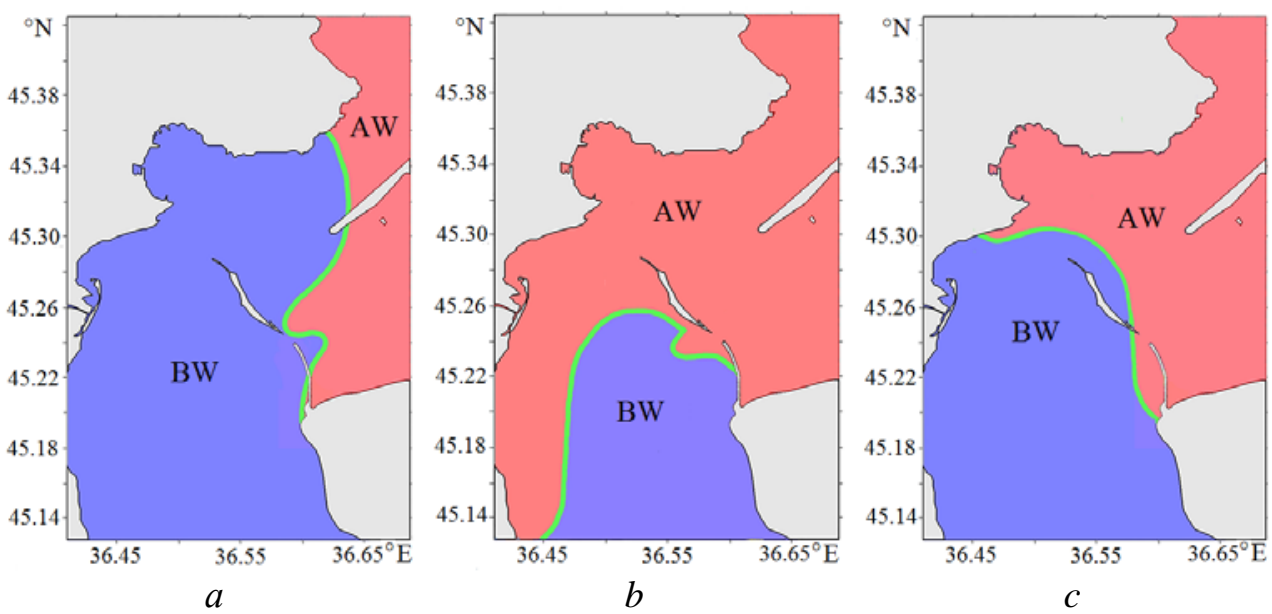

F i g. 1. Scheme of the northern $(a)$, southern $(b)$ and middle $(c)$ positions of the haline front in the Kerch Strait in 2001-2014 (AW and BW denote the Azov Sea and the Black Sea waters, respectively)

Each probing contains data on synchronously measured vertical distributions of temperature, salinity, total suspended matter concentration and fDOM. Therefore, according to the salinity, the field of which is divided by a clearly expressed front, it is possible to determine the correspondence of the measured parameters to the Azov and Black Sea types of waters.

According to the salinity criteria S $<13$ PSU (the Sea of Azov waters of the strait), $\mathrm{S}>16$ PSU (the Black Sea waters of the strait), two samples of sounding $\mathrm{fDOM}(\mathrm{z})$ were formed, within each sample the corresponding typical features were identified, statistical indicators of the considered value content variability on the sea surface were calculated and analyzed.

As a result of the analysis of the shape of the actual fDOM(z) profiles for three samples in the Kerch Strait, three qualitatively different types of waters with their own signs of vertical stratification of the considered value content field were conditionally identified (Fig. 2-4), different colors of the fDOM(z) profiles were used for better understanding of the graphic material): the Sea of Azov (type A), characteristic of the "clean" waters of the Sea of Azov, remote from anthropogenic objects; the Black Sea (type B), which characterizes the "clean" Black Sea waters that also do not experience anthropogenic impact; anthropogenically transformed (ANT type), which identifies the structure of waters with an anthropogenic component of fDOM, regardless of whether it belongs to type A or B. Below is a description of each of the identified types of vertical structure of the fDOM concentration field.

Type A -"clean" Sea of Azov waters, characterized by weakly expressed vertical stratification (or its absence) in the concentration field of the studied quantity. Sometimes in a narrow bottom layer of $0.2-0.5 \mathrm{~m}$ thickness, a slight increase in the fDOM content was observed (Fig. 2, $a$ ). 


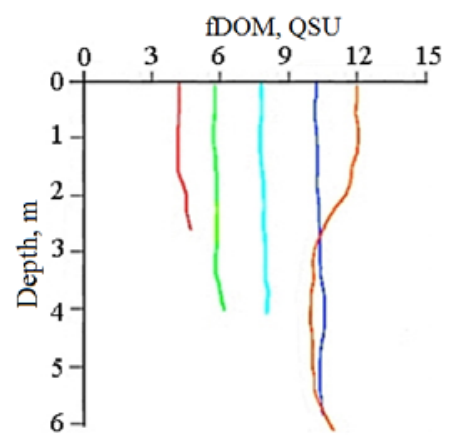

$a$

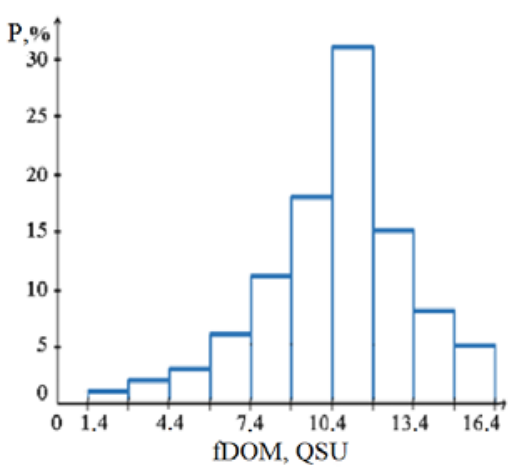

$b$

F i g. 2. Typical fDOM(z) profiles characteristic of the Azov Sea waters (a), and the corresponding histogram of the fDOM concentration repeatability for the sea surface layer $(b)$

The lack of stratification in the Sea of Azov waters is associated with the shallowness of this type area. The average depth of the northern Kerch Strait, where the transformed Sea of Azov waters prevail, is $4.5 \mathrm{~m}$. As a result of the intense vertical exchange, the fields of temperature, salinity and fDOM concentration here are vertically homogeneous for most of the year.

The statistical characteristics of the fDOM concentration distribution for type A waters on the sea surface, calculated using a sample of $\mathrm{n}=337$, are as follows: the range of variability $\Delta=1.4-16.3 \mathrm{QSU}$; average $\mathrm{fDOM}_{\mathrm{av}}=10.5 \mathrm{QSU}$; standard deviation $\sigma=2.4 \mathrm{QSU}$; modal value $\mathrm{fDOM}_{\text {mod }}=11.2 \mathrm{QSU}$; the repeatability of the mode $\mathrm{P}=31 \%$. Histogram of this type repeatability has a left-sided asymmetry (the modal value is greater than the average) (Fig. 2, b). The Sea of Azov type of field stratification of the studied value is located to the north of the haline front of the Kerch Strait (Fig. 1).
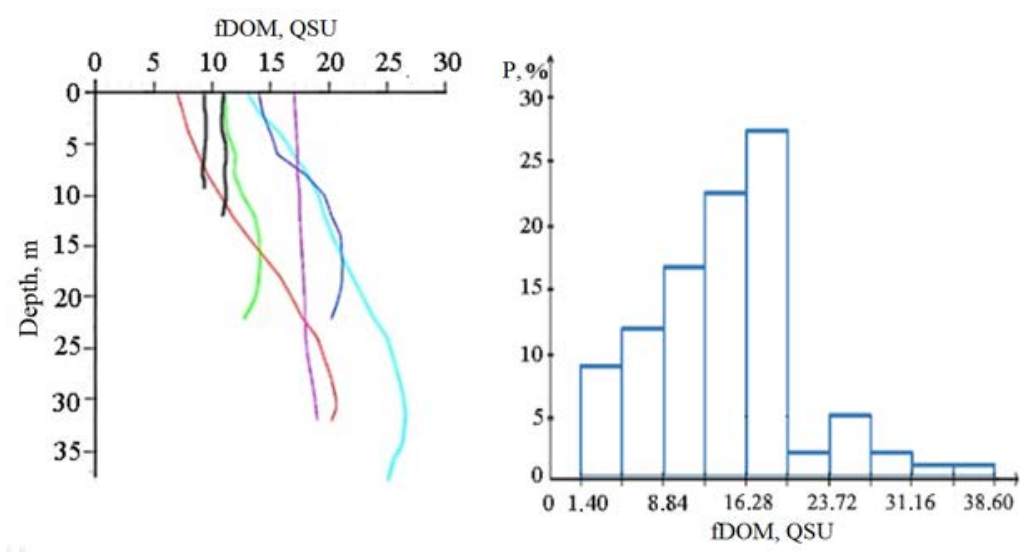

$b$

F i g. 3. Typical fDOM(z) profiles characteristic of the Black Sea waters (a), and the corresponding histogram of the fDOM concentration repeatability for the sea surface layer $(b)$ 
Type B - "clean" Black Sea waters, which are characterized by the presence of a subsurface maximum of the fDOM content in the southern deep-water part of the Kerch Strait and in the Black Sea pre-strait at a depth of 10-40 m, approximately in the density jump layer. In the Black Sea pre-strait, the fDOM concentration at the maximum horizon reached 32-42 QSU. In the southern Kerch Strait, in shallow water, this extremum is interrupted by the bottom. Therefore, the field of the studied value in the "clean" Black Sea waters of the strait in areas with depths less than $10 \mathrm{~m}$ is uniform along the vertical (Fig. 3, $a$ ).

Note that, similarly to the fDOM concentration field structure, the subsurface maximum in the Black Sea was revealed in the DOC concentration field [1, 15]. According to [1], this extremum, located at a depth of 10-50 m, is typical for the Black Sea Rim Current waters. The authors of [15] determined the time-stable maximum of DOC concentration detected at a depth of 20-60 m as a characteristic sign of vertical stratification of this value field in the Black Sea.

Histogram of the fDOM concentration frequency on the sea surface in type B waters is qualitatively different from the histogram of type A and has two modes provided by the data. In the area of high fDOM concentration, the second mode is clearly distinguished with values of 20.0-38.6 QSU (their total repeatability is $11 \%$ ) and a maximum of 25.6 QSU (5\%) (Fig. 3, b).

The data corresponding to this range of fDOM concentration were obtained by us during two expeditions in August and September 2011 with a stable northwestern wind, which caused a surge and rise effect to the sea surface in the southern Kerch Strait of the Black Sea subsurface waters, where the fDOM content reached 38.5 QSU (Fig. 3, b).

The most intense surge upwelling in the Kerch Strait is caused by the northwestern wind (https://meteopost.com/info/Upwelling/), and, according to [16], the frequency of wind in this direction during the year is $17 \%$, this is the second significance of recurrence for the Kerch region. Therefore, it can be assumed that local wind upwelling is a significant factor contributing to the water column saturation with dissolved organic matter in the southern part of the strait, which in the ascending circulation system comes from the subsurface structural zone of the Black Sea.

The indicator of the dissolved organic matter concentration in the marine environment is a direct function of illumination [15]. In addition to the upwelling effect, the increased fDOM content in the Black Sea waters of the strait in comparison with the Sea of Azov waters can be explained by their different turbidity and, accordingly, illumination. According to [17], the turbidity values (TSM concentration) in the Azov and Black Sea waters of the Kerch Strait are in a ratio of 3:1. Therefore, the ratio of illumination indicators in the Azov and Black Sea waters will be the opposite, and the fDOM content in the Sea of Azov waters will be lower.

The statistical characteristics of the fDOM concentration distribution of the type B waters on the sea surface, calculated using a sample of $n=178$, are as follows: the range of variability $\Delta=1.5-38.6$ QSU; average $\mathrm{fDOM}_{\mathrm{av}}=15.2 \mathrm{QSU}$; standard deviation $\sigma=5.8 \mathrm{QSU}$; modal value $\mathrm{fDOM}_{\bmod }=18.1 \mathrm{QSU}$; the fundamental mode repeatability is $\mathrm{P}=28 \%$. Compared to the Sea of Azov, 
the Black Sea waters in the Kerch Strait are distinguished by higher statistical indicators of the variability of the fDOM concentration field (Fig. 3, b).

Based on the statistical estimates of our data accumulated during numerous expeditions, it has been established that in the open Black Sea waters near Crimea in the 0-20 m layer, the fDOM content field is uniform. Its characteristic concentration varies within 14.9-20.0 QSU at a salinity of 18.2-18.4 PSU, which corresponds to the values of the average and most frequently repeated fDOM concentration in the "clean” Black Sea waters of the Kerch Strait. These waters are located to the south of the haline front of the Kerch Strait (Fig. 1).

The ANT type waters differ from the two types discussed above on a quantitative and qualitative level. The fDOM concentration in waters of this type is significantly higher than in waters of types A and B (Fig. 2-4).

The area of ANT type waters is represented by individual spots (lenses) with a high concentration of the studied value. Sometimes they stood out visually, in terms of transparency and color. The most significant such formations had a horizontal scale of 1-6 miles.

The ANT type fDOM(z) profile differs from the "smooth" profiles characteristic of the "clean" waters of the Azov and Black seas interacting in the strait. Here fDOM(z) is a non-monotonic function of depth with a characteristic rugged shape, indicating the presence of intrusive formations with a high content of dissolved organic matter. Separate layers and thin interlayers are noted in the water column, where the fDOM concentration is significantly increased. These properties, as well as the locations of areas with stratification signs by the ANT type, indicate the anthropogenic fDOM presence in waters of this type (Fig. 4, a).
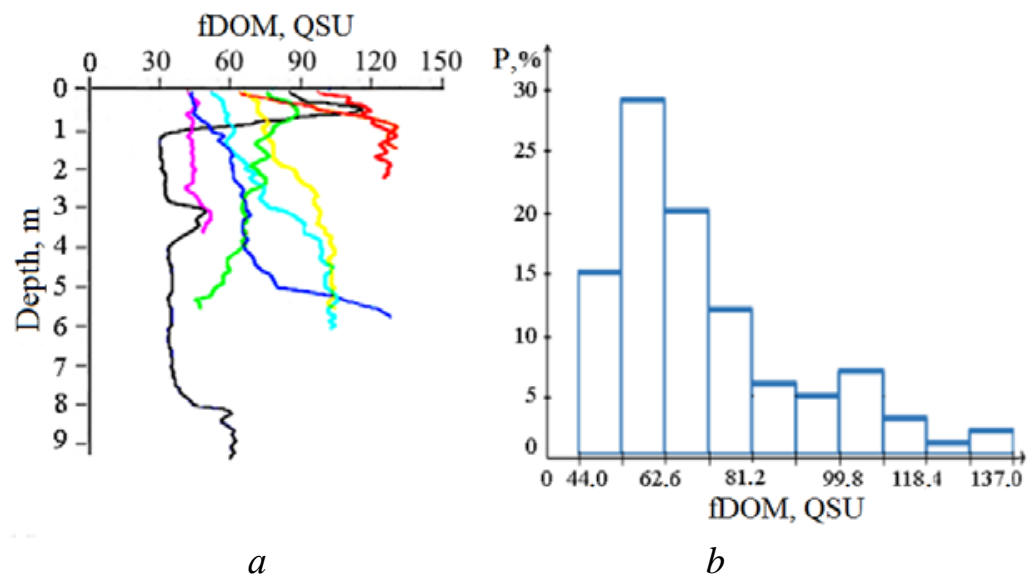

F i g. 4. Typical $f D O M(z)$ profiles characteristic of the waters containing the anthropogenic fDOM component (a), and the corresponding histogram of the fDOM concentration repeatability for the sea surface layer $(b)$

The empirical distribution of fDOM concentration in ANT type waters is characterized by right-handed asymmetry (the modal value is less than the average) and the following statistical characteristics, calculated using a sample of $n=103$ : the range of variability $\Delta=44-137$ QSU; average $\mathrm{fDOM}_{\mathrm{av}}=73.1 \mathrm{QSU}$; standard 
deviation $\sigma=14.2$ QSU; modal value $\mathrm{fDOM}_{\text {mod }}=58.0$ QSU; the repeatability of the mode $P=29 \%$ (Fig. $4, b$ ).

Unlike types A and C, type ANT has no analogue in a thermohaline field. This means that water areas with ANT type features are not manifested in the structure of the temperature and salinity fields, and the corresponding formations in the fDOM field are of artificial nature.

Structures of the type ANT have been found throughout the entire Kerch Strait water area. Location of lenses with a high concentration of the studied value in the considered water area is not accidental. They were located off the coast of the strait and in the sea, close to the main economic facilities of the region (ports, cargo terminals, offshore transshipment points, dumping zones of the soil seized during dredging and sewage collectors).

On the diagrams of the horizontal distribution of the fDOM concentration, the water areas of this type were distinguished in the form of local maxima (spots, lenses), within which the concentration of the considered substance significantly exceeded the background values. Lenses with anthropogenic fDOM content, as a rule, had well-defined boundaries, their characteristic horizontal scale is $~ 1-6$ miles.

This feature is shown in Fig. 5, which gives the horizontal distribution of the fDOM concentration in the Kerch Bay according to the data of the expedition carried out by the MHI in May 2005 [18]. Two large-scale lenses of waters with a diameter of 4-6 miles and fDOM content in the center of 105-120 QSU are visible.

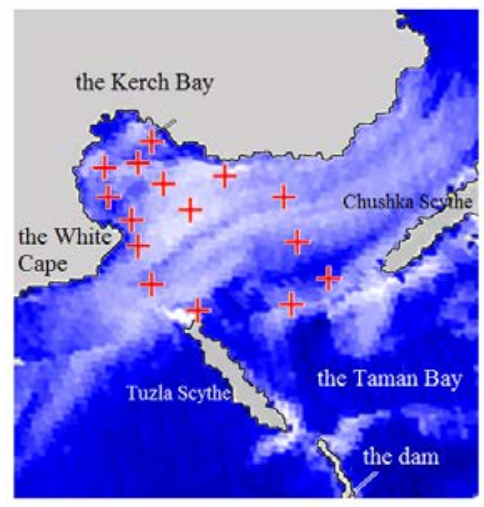

$a$

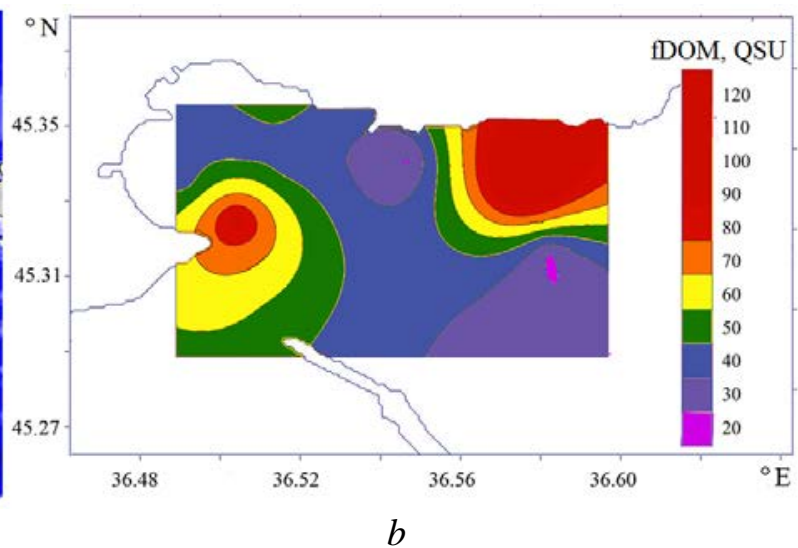

F i g. 5. Scheme of the stations in the satellite image (a), and distribution of the fDOM concentration at the $3 \mathrm{~m}$ horizon in the Kerch Bay in May, 2005 (b)

The fDOM stratification inside the lenses corresponded to the type ANT. In terms of area, each of them is comparable to the area of the Kerch Bay water area. The lens core in the southwestern part of the bay was located in the vicinity of the oil terminal located at White Cape. With this object, the fDOM excess content is associated with in the surrounding waters.

Another lens, judging by the thermohaline features and satellite information, was removed from the Sea of Azov. About a fourth of its area was located within the polygon, the rest was in the Azov-side narrowness of the strait. 
Note that fDOM concentration fields with ANT type features were monitored during MHI expeditions in the known polluted coastal waters of Crimea - in the Feodosiya Gulf, Dnieper-Bug estuary, Balaklava and Yuzhnaya bays (Sevastopol).

Fig. 6 shows the scheme of Kerch Strait water area zoning according to the typical features of vertical stratification of the fDOM concentration field. The boundary between types A and B is drawn along the line (shown in red) corresponding to the average position of the frontal section in the salinity field during the observation period.

The area of ANT type waters is represented by separate numbered spots: 1 water area adjacent to the release of treatment facilities in Kerch; 2-5 - areas of landfills; 6, 7 - points of road transshipment of goods; 8-11 - approaches to ports; 12 - oil terminal; 13 - lens of polluted waters taken out from the Sea of Azov.

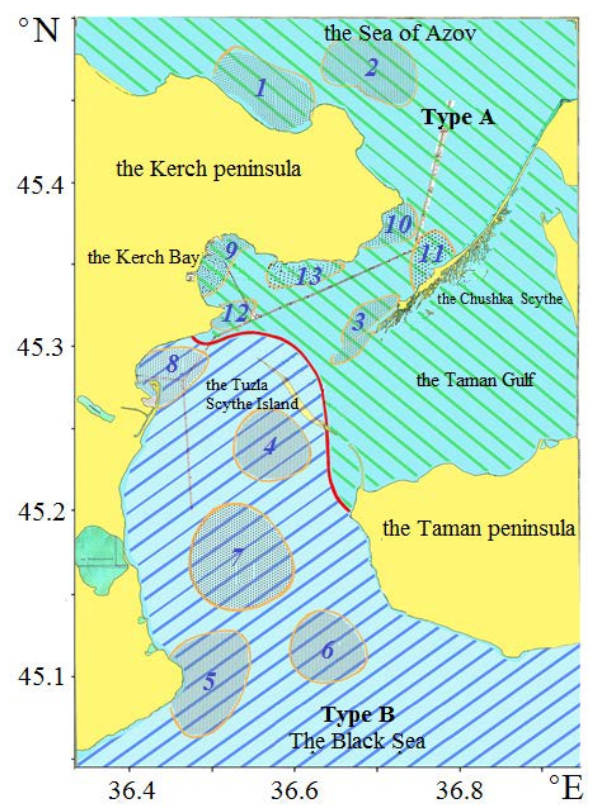

F i g. 6. Scheme of the Kerch Strait water area zoning according to the typical features of vertical stratification of the fDOM concentration field

\section{Conclusion}

Based on the materials of a series of expeditions carried out by Marine Hydrophysical Institute in 2001-2014, typical signs of vertical stratification of the concentration field of colored dissolved organic matter (fDOM) in the Kerch Strait were revealed. Based on these features, a zoning scheme for the water area under study is proposed. Boundaries separating the typical structures and the statistical characteristics of the fDOM concentration distribution for the area of each type are analyzed.

The following three types of structure of the fDOM content field, which qualitatively differed in the $\mathrm{fDOM}(\mathrm{z})$ profile shape and the empirical distribution of this substance concentration on the sea surface were conventionally distinguished: 
- type A -transformed waters of the Sea of Azov without the anthropogenic fDOM component. This type is characterized by the vertical stratification absence in the field of the considered value. Histogram of this type of the fDOM concentration repeatability on the sea surface has left-sided asymmetry, modal value is $11.8 \mathrm{QSU}$, mode repeatability is $31 \%$, average value is $9.8 \mathrm{QSU}$, standard deviation is $2.4 \mathrm{QSU}$;

- type B - transformed waters of the Black Sea that do not contain the anthropogenic fDOM component. This type is characterized by the fDOM(z) distribution with a subsurface maximum. The histogram of this type of the fDOM concentration repeatability contains two modes. The fundamental mode value is 18.1 QSU, its repeatability is $28 \%$, the average value is $15.2 \mathrm{QSU}$, and the standard deviation is 5.8 QSU. The second, less significant mode is the indicator of the release of fDOM-saturated sub-surface Black Sea waters into the Black Sea part of the Kerch Strait in the system of ascending circulation of wind upwelling;

- type ANT. It includes waters with an anthropogenic component in the fDOM concentration field; it is distinguished by a high concentration and a nonmonotonic $\mathrm{fDOM}(\mathrm{z})$ profile with intrusive features. Histogram of this type of fDOM concentration repeatability has right-sided asymmetry, modal value is 58.0 QSU, mode repeatability is $29 \%$, average value is 73.1 QSU, standard deviation is 14.2 QSU.

Boundary between the Azov and Black Sea water types is represented by the haline front. At the western Kerch Strait, the front experienced significant meridional displacements on a synoptic scale with a span of $\sim 20$ miles. In the center and in the east of the strait, the front position was relatively stable, its centerline approximately coincided with the line Tuzla Island - the dam.

Area of the structure of ANT type waters on the horizontal distributions of the studied value concentration was distinguished in the form of separate local maxima. As a rule, these spots (lenses) had well-defined boundaries, the horizontal scale of the most significant lenses was $\sim 1-6$ miles.

It is shown that the lower fDOM content in the Azov Sea waters as compared to the Black Sea waters is due to the wind upwelling observed in the Black Sea prestrait and better illumination of the Black Sea waters of the Kerch Strait due to the reduced turbidity.

\section{REFERENCES}

1. Agatova, A.I., Lapina, N.M. and Torgunova, N.I., 2018. Features of the Distribution of Organic Matter in the Waters of the Black Sea. In: A. P. Lisitzin, ed., 2018. The Black Sea System. Moscow: Scientific world, pp. 146-170. doi:10.29006/978-5-91522-473-4.2018.146

2. Matishov, G., Matishov, D., Gargopa, Yu., Dashkevich, L., Berdnikov, S., Baranova, O. and Smolyar, I., 2006. Climatic Atlas of the Sea of Azov 2006. NOAA Atlas NESDIS 59. Washington, DC: U.S. Government Printing Office, 2006. 103 p. Available at: https://www.nodc.noaa.gov/OC5/AZOV2006/start.html [Accessed: 17 August 2021].

3. Shanmugam, P., Varunan, T., Jaiganesh, S.N.N., Sahay, A. and Chauhan, P., 2016. Optical Assessment of Colored Dissolved Organic Matter and Its Related Parameters in Dynamic Coastal Water Systems. Estuarine, Coastal and Shelf Science, 175, pp. 126-145. https://doi.org/10.1016/j.ecss.2016.03.020 
4. Stedmon, C.A., Markager, S. and Bro, R., 2003. Tracing Dissolved Organic Matter in Aquatic Environments Using a New Approach to Fluorescence Spectroscopy. Marine Chemistry, 82(3-4), pp. 239-254. doi:10.1016/S0304-4203(03)00072-0

5. Saraceno, J.F., Pellerin, B.A., Downing, B.D., Boss, E., Bachand, P.A.M. and Bergamaschi, B.A., 2009. High-Frequency In Situ Optical Measurements during a Storm Event: Assessing Relationships between Dissolved Organic Matter, Sediment Concentrations, and Hydrologic Processes. Journal of Geophysical Research: Biogeosciences, 114(G4), G00F09. doi:10.1029/2009JG000989

6. Downing, B.D., Pellerin, B.A., Bergamaschi, B.A, Saraceno, J.F. and Kraus, T.E.C., 2012. Seeing the Light: The Effects of Particles, Dissolved Materials, and Temperature on In Situ Measurements of DOM Fluorescence in Rivers and Streams. Limnology and Oceanography: Methods, 10(10), pp. 767-775. doi:10.4319/lom.2012.10.767

7. Ji, Z.-G., 2017. Hydrodynamics and Water Quality: Modeling Rivers, Lakes, and Estuaries. Hoboken, USA: John Wiley \& Sons Inc., 612 p. https://doi.org/10.1002/9781119371946

8. Chepyzhenko, A.I. and Chepyzhenko, A.A., 2017. Methods and Device for In Situ Dissolved Organic Matter (DOM) Monitoring in Natural Waters' Environment. In: SPIE, 2017. Proceedings of SPIE. Vol. 10466: 23rd International Symposium on Atmospheric and Ocean Optics: Atmospheric Physics. 104663S. doi:10.1117/12.2287797

9. Pugach, S.P. and Pipko, I.I., 2013. Dynamics of Colored Dissolved Matter on the East Siberian Sea Shelf. Doklady Earth Sciences, 448(1), pp. 153-156. https://doi.org/10.1134/S1028334X12120173

10. Karlsson, C.M.G., Cerro-Gálvez, E., Lundin, D., Karlsson, C., Vila-Costa, M. and Pinhassi, J., 2019. Direct Effects of Organic Pollutants on the Growth and Gene Expression of the Baltic Sea Model Bacterium Rheinheimera sp. BAL341. Microbial Biotechnology, 12(5), pp. 892-906. doi:10.1111/1751-7915.13441

11. Boss, E., Pegau, W.S., Zaneveld, J.R.V. and Barnard, A.H., 2001. Spatial and Temporal Variability of Absorption by Dissolved Material at a Continental Shelf. Journal of Geophysical Research: Oceans, 106(C5), pp. 9499-9507. doi:10.1029/2000JC900008

12. Tedetti, M., Longhitano, R., Garcia, N., Guigue, C., Ferretto, N. and Goutx, M., 2012. Fluorescence Properties of Dissolved Organic Matter in Coastal Mediterranean Waters Influenced by a Municipal Sewage Effluent (Bay of Marseilles, France). Environmental Chemistry, 9(5), pp. 438-449. doi:10.1071/EN12081

13. Fedorov, K.N., 1984. The Physical Nature and Structure of Oceanic Fronts. New York: SringerVerlag, 333 p. doi:10.1029/LN019

14. Il'in, Yu.P., Fomin, V.V., D'yakov, N.N. and Gorbach, S.B., 2009. [Hydrometeorological Conditions of the Seas of Ukraine. Vol. 1. The Sea of Azov]. Sevastopol, 401 p. (in Russian).

15. Agatova, A.I., Burlakova, Z.P., Eremeeva, L.V. and Torgunova, N.I., 1992. Dissolved and Suspended Organic Matter in the Black Sea during the Winter-Spring Period. In: Eremeev, V.N., 1989. Complex Oceanographic Research on the Black Sea. Utrecht: CRC Press, pp. 121-130. doi:10.1201/B12069

16. Lomakin, P.D., Panov, D.B. and Spiridonova, E.O., 2010. Specific Features of the Interannual and Seasonal Variations of Hydrometeorological Conditions in the region of Kerch Strait for the Last Two Decades. Physical Oceanography, 20(2), pp. 109-121. doi:10.1007/s11110-0109071-5

17. Lomakin, P.D., Chepyzhenko, A.I. and Chepyzhenko, A.A., 2017. The Total Suspended Matter Concentration Field in the Kerch Strait Based on Optical Observations. Physical Oceanography, (6), pp. 58-69. doi:10.22449/1573-160X-2017-6-58-69

18. Lomakin, P.D., Chepyzhenko, A.I., Panov, B.N. and Borovskaya, R.V., 2006. Hydrological Conditions and Characteristics of Pollution of Kerch Strait Water in May 2005 on Base of Contact Measurements and Satellite Observations. Issledovanie Zemli iz Kosmosa, (4), pp. 2734 (in Russian). 
About authors:

Pavel D. Lomakin, Leading Research Associate, Marine Hydrophysical Institute of RAS (2 Kapitanskaya St., Sevastopol, 299011, Russian Federation), Ph. D. (Geogr.), Professor, ResearcherID: V-7761-2017, p_lomakin@mail.ru

Alexey I. Chepyzhenko, Senior Research Associate, Marine Hydrophysical Institute of RAS (2 Kapitanskaya St., Sevastopol, 299011, Russian Federation), Ph. D. (Tech. Sci.), SPIN-код: 35999653, Scopus Author ID: 6504344211, IstinaResearcherID (IRID): 6647872, ecodevice@yandex.ru

Anna A. Chepyzhenko, Junior Research Associate, Marine Hydrophysical Institute of RAS (2 Kapitanskaya St., Sevastopol, 299011, Russian Federation), ResearcherID: F-9651-2014, Scopus Author ID: 56536937200, annachep87@yandex.ru

Contribution of the co-authors:

Pavel D. Lomakin - general scientific supervision of the research; formulation of the study aims; selection of methods and approaches to their solution, assessment of the information capacity of the original empirical database, writing and editing the main text of the paper

Alexey I. Chepyzhenko - participation in the development of programs for several expeditionary integrated oceanological studies of the Kerch Strait, preparation of the Kondor Optical Probing Complex for oceanographic studies; initial data processing; presentation of the main graphic material, writing the main text of the paper

Anna A. Chepyzhenko - participation in the development of programs for several expeditionary integrated oceanological studies of the Kerch Strait, expeditionary work; observation of currents, temperature, salinity, TSM and DOM concentrations; initial data processing; presentation of the main graphic material, editing the main text of the paper

All the authors have read and approved the final manuscript.

The authors declare that they have no conflict of interest. 